\title{
Evidence on the effect of uncontrolled diabetes mellitus on orthodontic tooth movement. A systematic review with meta-analyses in pre-clinical in-vivo research
}

\author{
Koletsi, Despina ; Iliadi, Anna ; Papageorgiou, Spyridon N ; Konrad, Daniel ; Eliades, Theodore
}

\begin{abstract}
Objective The aim of this review was to appraise the existing evidence from pre- clinical research on tooth movement under the condition of hyperglycemic status. Design Electronic search was conducted in 8 databases in October 13, 2019, to identify related pre- clinical animal research with keywords being: "diabetes mellitus", "tooth movement". Eligibility criteria involved controlled animal studies, entailing tooth movement under diabetic status compared to control healthy animals. Primary endpoints involved all outcomes related to tooth movement. Risk of bias (RoB) was assessed through the SYstematic Review Centre for Laboratory animal Experimentation tool (SYRCLE), while quantitative synthesis was planned after exploration of heterogeneity, through random effects meta-analyses of standardized mean differences (SMDs) with $95 \%$ confidence intervals (CIs). Results Of an initial number of 290 articles retrieved, 14 papers were eligible for inclusion in the qualitative synthesis, while 9 contributed to meta-analyses. Heterogeneity of experimental conditions in individual studies was evident. The risk of bias overall was rated as unclear to high. There was no evidence of a significant effect of diabetes mellitus when tooth movement was assessed macroscopically (6 studies, SMD: 1.47; 95 \% CI: $-0.60,3.53$; $\mathrm{p}=0.16$ ). However, attenuation of osteoblastic differentiation within the periodontal ligament was detected, as there was evidence of reduction of osteopontin expression (2 studies, SMD: $-3.77 ; 95 \% \mathrm{CI}:-4.89,-2.66 ; \mathrm{p}<0.001$ ). Conclusions There is currently a paucity of solid evidence with regard to alterations of the equilibrium of the implicated structures under the status of diabetes mellitus, when mechanical stimulation of teeth is attempted, with sporadic inferences from animal research. Significant research insights in how the disease impacts on orthodontic tooth movement are invaluable, at present.
\end{abstract}

DOI: https://doi.org/10.1016/j.archoralbio.2020.104739

Posted at the Zurich Open Repository and Archive, University of Zurich

ZORA URL: https://doi.org/10.5167/uzh-190619

Journal Article

Accepted Version

Originally published at:

Koletsi, Despina; Iliadi, Anna; Papageorgiou, Spyridon N; Konrad, Daniel; Eliades, Theodore (2020). Evidence on the effect of uncontrolled diabetes mellitus on orthodontic tooth movement. A systematic review with metaanalyses in pre-clinical in- vivo research. Archives of Oral Biology, 115:104739.

DOI: https://doi.org/10.1016/j.archoralbio.2020.104739 
Evidence on the effect of uncontrolled diabetes mellitus on orthodontic tooth movement. A systematic review with meta-analyses in pre-clinical in- vivo research

Despina Koletsi $\mathrm{a}^{\mathrm{a},}{ }^{,}$, Anna Iliadi ${ }^{\mathrm{b}}$, Spyridon N. Papageorgioua ${ }^{\mathrm{a}}$, Daniel Konrad ${ }^{\mathrm{c}, \mathrm{d}}$ and Theodore Eliades ${ }^{\mathrm{a}}$

${ }^{a}$ Clinic of Orthodontics and Pediatric Dentistry, School of Dental Medicine, University of Zurich, Switzerland

${ }^{\mathrm{b}}$ Department of Biomaterials, School of Dentistry, National and Kapodistrian University of Athens, Greece

${ }^{c}$ Division of Pediatric Endocrinology and Diabetology, University Children's Hospital, Zurich, Switzerland

${ }^{d}$ Children's Research Center, University Children's Hospital, Zurich, Switzerland

Publication:

Koletsi D, Iliadi A, Papageorgiou SN, Konrad D, Eliades T. Evidence on the effect of uncontrolled diabetes mellitus on orthodontic tooth movement. A systematic review with meta-analyses in preclinical in- vivo research. Arch Oral Biol. 2020 Jul;115:104739. doi: 10.1016/j.archoralbio.2020.104739. Epub 2020 May 11.

*Correspondence: Despina Koletsi, Clinic of Orthodontics and Pediatric Dentistry, Center of Dental Medicine, University of Zurich, Plattenstr. 11, 8032 Zurich, Switzerland. E-mail: d.koletsi@gmail.com 


\section{Structured Abstract}

Objective: The aim of this review was to appraise the existing evidence from pre- clinical research on tooth movement under the condition of hyperglycemic status.

Design: Electronic search was conducted in 8 databases in October 13, 2019, to identify related preclinical animal research with keywords being: "diabetes mellitus", "tooth movement". Eligibility criteria involved controlled animal studies, entailing tooth movement under diabetic status compared to control healthy animals. Primary endpoints involved all outcomes related to tooth movement. Risk of bias (RoB) was assessed through the SYstematic Review Centre for Laboratory animal Experimentation tool (SYRCLE), while quantitative synthesis was planned after exploration of heterogeneity, through random effects meta-analyses of standardized mean differences (SMDs) with $95 \%$ confidence intervals (Cls).

Results: Of an initial number of 290 articles retrieved, 14 papers were eligible for inclusion in the qualitative synthesis, while 9 contributed to meta-analyses. Heterogeneity of experimental conditions in individual studies was evident. The risk of bias overall was rated as unclear to high. There was no evidence of a significant effect of diabetes mellitus when tooth movement was assessed macroscopically ( 6 studies, SMD: $1.47 ; 95 \% \mathrm{Cl}:-0.60,3.53 ; \mathrm{p}=0.16$ ). However, attenuation of osteoblastic differentiation within the periodontal ligament was detected, as there was evidence of reduction of osteopontin expression ( 2 studies, SMD: $-3.77 ; 95 \% \mathrm{Cl}:-4.89,-2.66 ; \mathrm{p}<0.001$ ).

Conclusions: There is currently a paucity of solid evidence with regard to alterations of the equilibrium of the implicated structures under the status of diabetes mellitus, when mechanical stimulation of teeth is attempted, with sporadic inferences from animal research. Significant research insights in how the disease impacts on orthodontic tooth movement are invaluable, at present.

Keywords: diabetes mellitus, hyperglycemia, tooth movement, periodontal ligament, orthodontic, systematic review 


\section{Introduction}

Diabetes Mellitus (DM) is a common metabolic disorder, characterized by deficiency of insulin secretion or action, leading to chronic hyperglycemia and disturbances of carbohydrate, fat, and protein metabolism (Chau, Edelman, \& Chandran, 2003; Verhaeghe et al., 1989). Type 1 DM is caused by an absence of insulin secretion, which results from an autoimmune destruction of pancreatic beta cells, and accounts for $5-10 \%$ of diabetic patients (Bensch, Braem, Van Acker, \& Willems, 2003; Burden, Mullaly, \& Sandler, 2001). Type 2 DM accounts for 90- 95\% of diabetic patients, representing variable degrees of insulin deficiency/ resistance (American Diabetes Association, 2009).

The broader orthopedics literature demonstrates that diseases presenting connective tissue manifestations such as Type $1 \mathrm{DM}$, demonstrate collagen degenerative processes affecting the tendons and/ or ligaments as well as alterations in bone metabolism (He et al., 2004; Liu et al., 2006). Orthodontic tooth movement comprises of multiple biological processes characterized by consecutive reactions of the periodontal tissue in response to biomechanical forces. During orthodontic tooth movement, a concurrent compression of the matrix takes place in the pressure site along with a tension in the opposite site, resulting in alveolar bone resorption and apposition respectively (Jónsdóttir, Giesen, \& Maltha, 2006; K. Papadopoulou et al., 2013). During tension the load is distributed to the collagen bundles and thus any reduction in their properties arising from structural defects, might bear unfavorable consequences for the integrity of the tissue (Jónsdóttir et al., 2006; K. Papadopoulou et al., 2013). Moreover, the mechanical stress or stretching generated during orthodontic movement causes controlled amounts of tissue injury that triggers the activation of inflammatory mediators, resulting in a completely new state of periodontal homeostasis. Therefore, inflammation is inbred when orthodontic induced tooth movement takes place.

The presence of diseases or conditions that modify inflammatory response, such as DM, may also change the host's response to orthodontic force (Villarino, Lewicki, \& Ubios, 2011). Due to the attenuated osteoblastic activity and the enhanced apoptosis of osteoblast cells, imbalances between bone apposition and resorption might be present in diabetic patients during orthodontic treatment (Najeeb et al., 2017). Furthermore, evidence suggests significant alterations in bone density in diabetic patients, even in patients under control with intensive insulin treatment 
(Guarneri, Weber, Gallia, \& Chiumello, 1993; Hofbauer, Brueck, Singh, \& Dobnig, 2007). When diabetes is uncontrolled or poorly controlled, severe degradation of periodontal tissues may occur, therefore contraindicating orthodontic treatment until the metabolic disorder is compensated (Bensch et al., 2003; Burden et al., 2001).

A systematic review from 2017 (Najeeb et al., 2017) was the sole source of synthesized evidence on the effects of uncontrolled diabetes mellitus on tooth movement pertaining to orthodontic treatment. However, this review included a limited number of individual studies, did not include a mathematical synthesis, ie. a meta-analysis, that would allow for a more precise estimation of the overall treatment effect, and focused on the rate and magnitude of tooth movement as an outcome of interest. Effectively, there is a timely need for a more complete approximation of the mechanisms underlying the effect of distorted metabolic status on the periodontal apparatus and mechanical stimulation resulting in tooth movement. As such, the aim of the present systematic review was to collect, synthesize and appraise existing evidence, from pre-clinical in vivo research, on any documented quantitative outcome related to tooth movement under the condition of hyperglycemic status. The null hypothesis of this research was that there is no difference in the effect of hyperglycemic or normoglycemic status on orthodontically induced tooth movement.

\section{Materials and Methods}

\section{Protocol Registration and Reporting}

The protocol for this work has been designed a priori and has been registered at the Open Science Framework (https://osf.io/f6ga4/) as of October 13, 2019. This systematic review was conducted according to the Cochrane Handbook (Cochrane Handbook for Systematic Reviews of Interventions, 2019) and followed the reporting schemes of the PRISMA statement (Liberati et al., 2009; Moher, Liberati, Tetzlaff, \& Altman, 2009).

\section{Eligibility Criteria}

The following inclusion criteria for study selection were applied in line with the Participants, Intervention, Comparator, Outcomes (PICO) guidance and modified accordingly for animal research: 
- Study Design: randomized or non-randomized experimental in- vivo studies involving animals and including a comparison group will be considered (one or more comparators)

- Population: all animal models undergoing any type of orthodontic tooth movement or mechanical stress in the periodontal ligament are considered eligible, of both gender, at any age, or species. On an exploratory basis, insulin/ other medication treated animals were considered as well.

- Intervention: tooth movement, or periodontal ligament mechanical stimulation in diabetic animals.

- Comparator: tooth movement, or periodontal ligament mechanical stimulation in control healthy animals, with no underlying diabetes mellitus.

- Outcomes (primary): Any quantitative outcome related to orthodontic tooth movement or stimulation of the periodontal ligament, including but not confined to: rate of tooth movement, root resorption, expression of inflammatory mediators, expression of genes related to osteoblastic/ osteoclastic differentiation, bone loss, osteoclast cells.

\section{Exclusion Criteria:}

- Animal studies with no comparison group

- Animal studies involving administration of pharmaceutical/exogenous hormones/molecules to populations

- Any outcome not related to tooth movement

\section{Search Strategy}

Electronic search was formulated and conducted by one author (DK) in eight databases for eligible published and unpublished research items. No language or chronologic restrictions were applied to the search. Specifically, the search was employed within: Medline via Pubmed, Scopus, Cochrane Central Register of Controlled Trials (CENTRAL), Cochrane Database of Systematic Reviews (CDSR), Open Grey, ClinicalTrials.gov (www.clinicaltrials.gov), National Research Register (ISRCTN: www.controlled-trials.com), PERGAMOS (pergamos.lib.uoa.gr, online repository of research theses and dissertations of the National and Kapodistrian University of Athens). In addition, hand search of the retrieved for full text evaluation articles was performed for any potential for inclusion publication. Access was sought in October 13, 2019 (Appendix A). Representative keywords included "tooth movement", "diabetes mellitus", "orthodontic movement". Initial screening for 
eligible articles was done by one reviewer (DK) and confirmed by a second (AI), with documented disagreements being resolved after consultation with a third reviewer (TE), who settled potential discrepancies.

\section{Data Extraction}

Data extraction was performed independently by one reviewer (Al), while confirmed by a second (DK) and all relevant information was extracted on standardized piloted forms. Initial piloting for data extraction was done in 30 percent of the included articles. Specifically, information on year of publication, origin, sample size, interventions/ comparators, outcomes, method of outcome assessment, timescale for the application of orthodontic force, as well as protocol for diabetes induction in animals, was recorded. Both reviewers were not blinded on study title and authorship.

\section{Risk of Bias Assessment in Individual Studies}

Risk of bias (RoB) in individual studies was assessed with the SYstematic Review Centre for Laboratory animal Experimentation (SYRCLE) RoB tool for animal studies (Hooijmans et al., 2014). In particular, the tool comprises of the following principal domains which were were considered: 1 . Sequence generation, 2. Baseline characteristics, 3. Allocation concealment, 4. Random housing, 5. Blinding of researchers, 6 . Random outcome assessment, 7. Blinding of outcome assessors, 8. Incomplete outcome data, 9. Selective outcome reporting, 10. Other sources of bias. An overall assessment of the risk of bias was made for each included study (high, unclear, low). Studies with at least 1 item designated to be at high risk of bias were regarded as having an overall high risk of bias. Reports with unclear risk of bias for one or more key domains were considered to be at unclear risk of bias and likewise, studies with low risk of bias in all domains were rated as low risk of bias.

Overall risk of bias assessment was done by one author (DK) after calibration with a second (AI) on 30 percent of the articles under consideration. Ratings were confirmed by the second author, while in cases of disagreements, a third author (TE) was consulted to settle down discrepancies.

\section{Summary Measures and Data Synthesis}

A quantitative synthesis was planned for all outcomes given the availability of the retrieved studies as well as the homogeneity on key domains. Clinical heterogeneity of the eligible for inclusion studies was assessed through the examination of study design/ settings, eligibility criteria, populations, interventions, experimental conditions and data collection methods. Statistical 
heterogeneity was examined through visual inspection of the confidence intervals (Cls) for the treatment effects on forest plots. A formal $\chi^{2}$ test was also applied to assess heterogeneity; a P value below the level of $10 \%(P<0.1)$ is considered indicative of significant heterogeneity $1^{2}$ (Higgins, Tompson, Deeks, \& Altman 2003). $I^{2}$ test for homogeneity was undertaken as well. As continuous outcomes were expected to be explored, values for each specific outcome were calculated through standardized mean differences (SMDs) with associated 95\% Confidence Intervals (95\% Cls). Random effects meta-analyses were conducted as they were considered more appropriate to reflect the expected heterogeneity and variations in laboratory settings, experimental conditions and variations in tooth movement related parameters.

\section{Risk of Bias Assessment Across Studies}

If more than ten studies were included in the meta-analyses, publication bias and small study effects were investigated through standard funnel plots (Sterne, Egger, \& Moher, 2011; Sterne et al., 2019) and Egger's regression test (Egger, Smith, Schneider, \& Minder, 1997).

\section{Additional Analyses}

Sensitivity analyses were preplanned to explore the effect of studies with high risk of bias and isolate the effect of lower risk of bias studies to the overall pooled estimate, in case both high and lower risk of bias studies being included in the quantitative synthesis.

In addition, when extremely high or low variability of relevant estimates were recorded in individual studies, then, sensitivity analyses were conducted to isolate and remove this effect.

All analyses were undertaken in Review Manager (RevMan 5.3) software (Review Manager (RevMan) [Computer program], 2014).

\section{Results}

\section{Search Details}

After electronic database and hand- searching, a total of 290 eligible articles were retrieved, with 19 papers left for full- text evaluation after duplicate removal, title and abstract screening. Finally, five articles were excluded for reasons related to our pre- defined eligibility criteria, leaving a number of 14 articles for inclusion in this systematic review (Figure 1) (Arita et al., 2016; Braga et 
al., 2011; Damanakis, 2018; Ferreira et al., 2018; Gomes et al., 2017, 2018; Li, Zhang, Wang, Feng, \& Bi, 2010; Maulana, Hikmah, Shita, Permatasari, \& Widyarti, 2014; Mena Laura et al., 2019; Plut et al., 2015; Santamaria-Jr et al., 2019; Sun et al., 2017; Villarino et al., 2011; Zhang, Li, \& Bi, 2011).

\section{Study design and characteristics}

All study characteristics and qualitative data are presented in Table 1.

Half of the included studies $(7 / 14 ; 50 \%)$ originated from South America, ie Brazil or Argentina, while 5 originated from Asia (36\%) and 2 from Europe (14\%). Publication years ranged from 2010 to 2019 with the preponderance of studies being published within the last 4 years $(8 / 14 ; 57 \%)$.

All but one study (Braga et al., 2011), recruited rats as animal models and specifically Wistar rats or Sprague- Dawley species (Arita et al., 2016; Damanakis, 2018; Ferreira et al., 2018; Gomes et al., 2017, 2018; Li et al., 2010; Maulana et al., 2014; Mena Laura et al., 2019; Plut et al., 2015; Santamaria-Jr et al., 2019; Sun et al., 2017; Villarino et al., 2011; Zhang et al., 2011). Braga et al, (2011) (Braga et al., 2011) recruited mice. Male rats were used with an age range from 4 to 14 weeks. For the majority of studies, diabetes status induction was achieved through the injection of variable concentrations of streptozotocin (9/14; 64\%) ranging from 20 to $120 \mathrm{mg} / \mathrm{kg}$. As an alternative, 4 studies used alloxane monohydrate in a concentration ranging from 40 to $150 \mathrm{mg} / \mathrm{kg}$ in a sterile saline solution, while only one study used an established model for non- obese type- II diabetes (Plut et al., 2015). Planned initial sample sizes ranged from 16 to 100 animals in total across the studies, with further breakdowns according to the formulated groups. Almost all studies used coil springs between molars and incisors of the animals to induce tooth movement. One used a helicoid spring, connecting the two contralateral molars (Villarino et al., 2011). Timescale for orthodontic force ranged from 8 to 42 days, for outcomes related to tooth movement and related conditions, while for biochemical analysis related outcomes 12 to 72 hours usually sufficed. According to the intended outcomes, the included studies used various methods of assessment, namely radiographs, casts, microcomputed tomography, histological, histomorhometric and immunohistochemical analysis and also gene expression and protein quantification.

\section{Risk of Bias within Studies}

The risk of bias of the included in- vivo animal studies was explored through the SYRCLE tool (Figure 2) (Hooijmans et al., 2014). In particular, 9 of 14 studies were rated as unclear risk of bias overall, 
leaving 5 studies presenting high risk of bias. Items that mostly contributed to the inspected high risk of bias were related to selection bias (sequence generation, baseline characteristics or allocation concealment). There was no definite information for any or the included studies as to whether housing of animals was done at random or otherwise, while there was also no reporting of blinding of investigators, caregivers or even outcome assessors, rendering the risk of bias status unclear for these domains. Three studies reported experience of animal loss, while all predetermined outcomes were reported in the results section of the included studies; however no research protocol could be identified for any of the included studies.

\section{Effects of Interventions, Meta-analyses, Additional Analyses}

In total, nine articles contributed to meta-analyses (Arita et al., 2016; Damanakis, 2018; Ferreira et al., 2018; Gomes et al., 2017, 2018; Mena Laura et al., 2019; Santamaria-Jr et al., 2019; Sun et al., 2017; Villarino et al., 2011), while there was a variable amount of outcomes across the included studies. Decision for mathematical synthesis of studies was made after consideration of the apparent homogeneity of the eligible studies. First, identification of similar outcomes was done; subsequently, consideration of experimental settings, populations and applied interventions was employed in an attempt to identify comparable and homogenous conditions.

Table 2 presents the quantitative data from meta-analyses as well as from individual study findings.

Specifically, when tooth movement was considered, there was no evidence of a significant effect of diabetes status on the overall orthodontically induced movement ( 6 studies, SMD: 1.47; 95\% Cl: $0.60,3.53 ; p=0.16$; Figure 3$)$, with an increased amount of heterogeneity documented across the contributing studies. Similarly, the concentration of osteoclast cells in the compression sites did not show any difference between diabetic and control animals under mechanical stress ( 3 studies, SMD: 1.35; 95\%Cl: -3.40, 6.10; P=0.58; Figure 4). However, evidence on key marker genes of osteogenesis such as osteopontin (OPN), as represented by immunoreactive cells for anti- OPN recorded 21 days after initiation of tooth movement, revealed a significantly lower concentration for the diabetic animals ( 2 studies, SMD: $-3.77 ; 95 \% \mathrm{Cl}:-4.89,-2.66 ; \mathrm{p}<0.001 ;$ Figure 5 ). This was also confirmed by a single study (Sun et al., 2017), that reported suppress of the differentiation associated increase in alkaline phosphatase (ALP) expression when diabetic status was confirmed (1 study, MD: $-0.09 ; 95 \% \mathrm{Cl}:-0.10,-0.08 ; \mathrm{P}<0.001)$. 
Further insights within this individual study showed evidence of increase in the cathepsin (CK) expression levels within compression sites of diabetic animals (MD: 0.18; 95\% Cl: 0.15, 0.21; p<0.001), as well as in the sclerostin (SOST) levels in tension sites (MD: 12; $95 \% \mathrm{Cl}: 10.57,13.43$; $\mathrm{p}<0.001)$. Other immunohistochemical findings revealed a significant decrease in dentin matrix protein- 1 cells (DMP-1) within tension sites of diabetic animals (MD: -17 ; 95\%Cl: $-18.51,-15.49$; $p<0.001)$.

Moreover, data from an individual study (Santamaria-Jr et al., 2019) revealed a significant increase in a number of protein inflammatory markers in the alveolar bone of diabetic rats. These included the fibroblastic growth factor bFGF (MD: 91.3; 95\% Cl: 72.46, 110.14; $p<0.001$ ), the transforming growth factor TGF- $\beta 1$ (MD: 96.05; 95\%Cl: 83.86, 108.24; $\mathrm{p}<0.001$ ) and the vascular endothelial growth factor VEGF (MD: 68.7; 95\%Cl: 57.03, 80.37; P<0.001). Findings from tension sites of the periodontal ligament of the animals after orthodontic tooth movement showed a significant decrease in the amounts of fibroblast cells in the diabetic group (MD: $-6.10 ; 95 \% \mathrm{Cl}:-8.39,-3.81$; $\mathrm{p}<0.001$ ), accompanied by a significant increase in the inflammatory cells (MD: 3; 95\%Cl: 1.04, 4.96; $p=0.003$ ). Regarding root resorption, only one study (Arita et al., 2016) reported on 2 related outcomes. First, on overall root resorption area, where a significantly lower amount of area crater were detected for the diabetic animals (MD: $-18.7 \times 10^{4} ; 95 \% \mathrm{Cl}:-24.45 \times 10^{4},-12.95 \times 10^{4} ; \mathrm{p}<0.001$ ). Second, on total root resorption volume, where in line with the previous finding, a significantly lower amount of resorption was recorded for the diseased animals (MD: $-9.8 \times 10^{6} ; 95 \% \mathrm{Cl}$ : $\left.14.65 \times 10^{6},-4.95 \times 10^{6} ; p<0.001\right)$.

Pre- planned analysis to substantiate the robustness of the retrieved findings after excluding high risk of bias studies was only applicable for the outcome tooth movement. After excluding the study of Santamaria et al., 2019 (Santamaria-Jr et al., 2019) due to the inspection of high risk of bias in more than 1 domains, again, no significant effects were detected in the pooled estimate (5 studies, SMD: $2.30 ; 95 \% \mathrm{Cl}:-0.15,4.74 ; \mathrm{p}=0.07$; Supplementary Figure 1). We further proceeded with a sensitivity analysis excluding the study of Damanakis, 2018 (Damanakis, 2018), after identifying a very low value of standard deviation of the data indicating extremely low variability compared with similar studies. Verification of this recording through communication with authors were confirmatory. In essence, after excluding this study, the overall pooled estimate remained nonsignificant (5 studies, SMD: 0.61; 95\%Cl: -1.43, 2.64; $\mathrm{p}=0.56$; Supplementary Figure 2). 
On an exploratory basis we examined the effect of diabetic versus insulin- treated diabetic animals. We found no evidence to suggest a difference between insulin- treated and uncontrolled diabetes animals in the recorded tooth movement after orthodontic induction (SMD: $-0.14 ; 95 \% \mathrm{Cl}:-1.84$, 1.56; $p=0.87$; Supplementary Figure 3).

Last, pre-planned analyses to explore publication bias and small study effects were ultimately not attempted due to the limited data and the small number of studies contributing to the quantitative syntheses.

\section{Discussion}

\section{Summary of the Evidence}

This systematic review was conducted and reported based on pre- clinical animal research in view of the lack of clinical studies in human. The findings reflect a wide spectrum of reported outcomes within the included studies. This resulted in a limited amount of data being synthesized to achieve increased precision in the reporting of the estimated effect for specific outcomes. The most represented was the reporting of tooth movement under conditions of health and disease with uncontrolled diabetic status. The null hypothesis was partially rejected. It was evident, that the inferences made for the effect of uncontrolled diabetes on orthodontic tooth movement were merely limited to the documented evidence of no significant effect macroscopically. Only one meta-analysis comprising of two studies was indicative of a decreased tendency for osteoblastic differentiation, related to the key marker gene of osteopontin when diabetic status was considered. Although the findings of both studies (Gomes et al., 2017, 2018) were indicative for a similar direction of the effect, the overall pooled estimate should be interpreted with caution, as these studies might have shared an experimental group; efforts were made to communicate with authors, however, they were unsuccessful.

To our knowledge this is the first systematic review with quantitative syntheses on mechanical stimulation of teeth targeting to subsequent tooth movement, under hyperglycemic metabolic conditions and compared to the physiologic normoglycemic status. Although our initial intention was to search for and document any clinical trial or prospective/ retrospective epidemiologic study with the involvement of patients or patient records of orthodontically treated individuals under the metabolic condition of diabetes, this was ultimately not applicable. There is a gap in the existing 
literature between human and animal research characterized by complete lack of evidence emerging from clinical research (Almadih et al., 2018; Burden et al., 2001), as no study could be identified except for isolated case reports (Maia, Monini, Jacob, \& Gandini, 2011; Reichert, Deschner, \& Jäger, 2009) while animal research has been identified as the sole source of evidence (Holtgrave, \& Donath, 1989; Najeeb et al., 2017).

Current reporting from basic research suggests that hyperglycemic environment may compromise connective tissue homeostasis and remodeling of the implicated structures (Guo, Chen, Zhang, Ding, \& Wang, 2018; Kato et al., 2016; Papadopoulou, Torado, Eliades, \& Kletsas, 2019). A laboratory study on human periodontal ligament (PDL) fibroblasts, being subjected to high glucose concentration under mechanical stretching conditions, has revealed the capacity of the simulated diabetic status to inhibit the documented effects of tensile stretching with regard to osteogenic differentiation potential, if applied in isolation (Papadopoulou et al., 2019). More specifically, PDL cells stretched under conditions of hyperglycemia have shown downregulation or attenuation of key genes or transcriptional factors such as osteopontin (OPN), alkaline phosphatase (ALP) and cfos. The results of one quantitative synthesis from the present review confirmed these findings for OPN, while for ALP, there was evidence in the same direction from an individual study, as no additional research findings were identified for this outcome. This is effectively important for patients undergoing orthodontic treatment, with compromised metabolism, as is the case with poorly controlled diabetes mellitus. In such patients who bear a challenging homeostasis, it might be inferred that loading conditions within the periodontal ligament, under the mechanisms of tooth movement, may be deteriorating for the tissue itself. It has also been claimed, that the effect of diabetes on stretch- induced PDL response might be partially attributed to the increased osmolality of the tissue which appears as a significant regulator (Mavrogonatou, \& Kletsas, 2012; Papadopoulou et al., 2019).

Furthermore, additional evidence from the retrieved studies at the histological and immunohistochemical level, reveal an increased amount of osteoclast cells within the periodontal ligament of the compressed tooth sites coupled with elevated cathepsin levels, aligned with augmented sclerostin levels within the tension sites (Sun et al., 2017). These findings present a possible potential of the diabetic status to dictate uncontrolled and excessive tooth movement, overshadowing the physiologic amounts, even when the periodontal apparatus appears intact. To the same line and through the use of molecular analytical techniques and protein quantification 
procedures, inflammatory markers as represented by endothelial or fibroblastic growth factors of the alveolar bone have been shown to increase their levels. This might be a reactive activity following the hampered organization of the collagen fiber network (Santamaria-Jr et al., 2019; Zhang et al., 2011).

Although significant alterations have been recorded at the molecular, or immunohistological level, the clear picture does not reveal itself macroscopically, if one looks at the amount of tooth movement in terms of diabetic and normoglycemic status. Evidence form the quantitative synthesis of six studies on tooth movement showed null effect. It is interesting that of the six studies combined, only one revealed no difference (Ferreira et al., 2018). Three of the studies (Damanakis, 2018; Gomes et al., 2018; Mena Laura et al., 2019) reported a significant effect of hyperglycemic status to promote increased tooth movement, while the other two revealed completely opposite findings (Arita et al., 2016; Santamaria-Jr et al., 2019). Only one of those studies assessed the magnitude of root resorption at the end of the corresponding tooth movement (Arita et al., 2016). Not surprisingly, for this specific study, this outcome was coupled with the reported findings on overall tooth movement, where the hyperglycemic conditions seemed to impose an attenuation in the amount of both movement and resorption. However, evidence from other studies is lacking. Possible explanations for the above- mentioned discrepancies between the studies are: differences in the induction of the hyperglycemic status or the notion of the levels of glucose that could be defined as excessive and corresponding to diabetes mellitus per se; limited timescale for tooth movement, pertaining to small amounts of movement; differences in settings, laboratory conditions or population samples used in each individual study. The last could also be confirmed by the apparent heterogeneity identified. With regard to the central outcome of tooth movement, as indicated by our exploratory analysis, we did not identify any difference between diabetic and insulin- treated animal populations, effectively confirming the findings of the aforementioned primary analysis and substantiating the potential for a limited experimental duration.

\section{Strengths and Limitations}

This review presents several strengths, being the first to include a quantitative synthesis of quite a few outcomes related to tooth movement under the condition of diabetes mellitus, resulting in increased precision of the estimated effect compared to data from individual single studies. Electronic search was extensive within eight databases of published and unpublished research and 
we followed a clear and transparent methodology in conducting and reporting the present systematic review. In addition, the protocol of this review was registered a priori to avoid significant deviations that could allow for selective reporting and its implications (Fleming, Koletsi, Dwan, \& Pandis, 2015).

However, some limitations also exist. The quantitative syntheses were actually employed but based on a limited number of studies; only for the outcome tooth movement there were 6 contributing studies and even in this synthesis it was not possible to search for and detect publication bias that might have a bearing on the retrieved findings. There may be a conceivable lack of complete certainty with regard to the evidence provided, as the individual studies identified and ultimately included, were not free from methodological limitations and serious risk of bias issues.

Extrapolation to human related conditions should be avoided in a direct manner, as there is a number of technical uncertainties and/ or experimental/ clinical conditions that are not to be translated to clinical practice; some examples are duration and timing of orthodontic treatment, orthodontic tooth movement under complete and uncontrolled hyperglycemic condition, as well as excessive force magnitude applications (Li et al., 2010; Sun et al., 2017; Theodorou, KuijpersJagtman, Bronkhorst, \& Wagener, 2019; Zhang et al., 2011). In addition, although we attempted to contact the authors of the studies in order to augment data contribution to the quantitative syntheses, this was actually not achieved, except in one case, due to the perceived reluctance of the authors to respond. Lack of standardization of laboratory settings and conditions related to diabetes induction, tooth movement, duration of experiments might have also contributed to the overall high levels of the documented heterogeneity across studies (Clarke, \& Williamson, 2016). Last, search strategy was implemented in a manner that would allow for an effectively wide initial inclusion of relevant articles under the spectrum of any article related to "tooth movement" and "diabetes". The specific inclusion of the term "root resorption" as an additional outcome term in the search slot was also prioritized, based on the fact that resorption is recognized as an important adverse outcome potentially related to orthodontic treatment and tooth movement in particular, and orthodontic tooth movement is frequently studied as a potential prognostic factor for root resorption (Currell, Liaw, Blackmore Grant, Esterman, \& Nimmo 2019; Weltman, Vig, Fields, Shanker, \& Kaizar, 2010). In any case, the inclusion of the term "root resorption" under the Boolean operator "OR" within the search strategy, is unlikely that would have resulted in bias or noninclusion of other outcome- specific articles. 


\section{Conclusions}

According the findings of this review and based on evidence from pre-clinical in vivo research, presence of hyperglycemia and background of diabetes mellitus is a regulator of immunohistochemical and inflammatory alterations within the periodontal ligament of teeth and supporting alveolar apparatus. Under mechanical stimulation, as represented by orthodontic tooth movement, this effect seems to be augmented towards the direction of attenuated osteoblastic differentiation; however, findings at the macroscopic level were not confirmatory in their entirety. In all, this is a field with complete lack of evidence form human research and any new effort should be directed towards exploring the effects of the human disease on tooth- bone interactions after mechanical stimulation. Otherwise, clinical practice and decisions for metabolically compromised patients proceeding for orthodontic treatment shall only be based on expert opinions and being grounded away from evidence.

\section{Acknowledgements}

We would like to thank Dr. Mena Laura and co- authors for providing data of their work and also Dr. George Damanakis for kindly providing information on his thesis.

\section{Conflict of Interest}

The authors have nothing to declare 
1. Medline via Pubmed

((diabetes) OR (diabetic) OR (diabetes mellitus)) AND ((tooth movement) OR (orthodontic) OR (orthodontic movement) OR (root resorption) OR (root remodeling))

2. Scopus

((diabetes) OR (diabetic) OR (diabetes mellitus)) AND ((tooth movement) OR (orthodontic) OR (orthodontic movement) OR (root resorption) OR (root remodeling))

3. Cochrane Central Register of Controlled Trials (CENTRAL)

((diabetes) OR (diabetic) OR (diabetes mellitus)) AND ((tooth movement) OR (orthodontic) OR (orthodontic movement) OR (root resorption) OR (root remodeling))

4. Cochrane Database of Systematic Reviews (CDSR)

((diabetes) OR (diabetic) OR (diabetes mellitus)) AND ((tooth movement) OR $\mathbf{0}$ (orthodontic) OR (orthodontic movement) OR (root resorption) OR (root remodeling))

5. Open Grey

(diabetes) AND (tooth movement)

(diabetes) AND (orthodontic)

6. ClinicalTrials.gov (www.clinicaltrials.gov)

(diabetes) AND (tooth movement)

(diabetes) AND (orthodontic)

7. National Research Register (ISRCTN: www.controlled-trials.com)

(diabetes) AND (tooth movement)

(diabetes) AND (orthodontic)

8. PERGAMOS (pergamos.lib.uoa.gr)

(diabetes) AND (tooth movement) 


\section{References}

Almadih, A., Al-Zayer, M., Dabel, S., Alkhalaf, A., Al Mayyad, A., Bardisi, W., Alshammari, S., \& Alsihati, Z. (2018). Orthodontic Treatment Consideration in Diabetic Patients. Journal of Clinical Medicine Research, 10(2), 77-81. https://doi.org/10.14740/jocmr3285w

American Diabetes Association. (2009). Diagnosis and Classification of Diabetes Mellitus. Diabetes Care, 32(Supplement 1), S62-S67. https://doi.org/10.2337/dc09-S062

Arita, K., Hotokezaka, H., Hashimoto, M., Nakano-Tajima, T., Kurohama, T., Kondo, T., Darendeliler, M. A., \& Yoshida, N. (2016). Effects of diabetes on tooth movement and root resorption after orthodontic force application in rats. Orthodontics \& Craniofacial Research, 19(2), 83-92. https://doi.org/10.1111/ocr.12117

Bensch, L., Braem, M., Van Acker, K., \& Willems, G. (2003). Orthodontic treatment considerations in patients with diabetes mellitus. American Journal of Orthodontics and Dentofacial Orthopedics: Official Publication of the American Association of Orthodontists, Its Constituent Societies, and the American Board of Orthodontics, 123(1), 74-78. https://doi.org/10.1067/mod.2003.53

Braga, S. M. G., de Albuquerque Taddei, S. R., Andrade, I., Queiroz-Junior, C. M., Garlet, G. P., Repeke, C. E., Teixeira, M. M., \& da Silva, T. A. (2011). Effect of diabetes on orthodontic tooth movement in a mouse model: Diabetes and orthodontic tooth movement. European Journal of Oral Sciences, 119(1), 7-14. https://doi.org/10.1111/j.1600-0722.2010.00793.x

Burden, D., Mullally, B., \& Sandler, J. (2001). Orthodontic treatment of patients with medical disorders. European Journal of Orthodontics, 23(4), 363-372. https://doi.org/10.1093/ejo/23.4.363

Chau, D. L., Edelman, S. V., \& Chandran, M. (2003). Osteoporosis and diabetes. Current Diabetes Reports, 3(1), 37-42. https://doi.org/10.1007/s11892-003-0051-8

Clarke, M., \& Williamson, P. R. (2016). Core outcome sets and systematic reviews. Systematic Reviews, 5(1), 11. https://doi.org/10.1186/s13643-016-0188-6

Cochrane Handbook for Systematic Reviews of Interventions. (2019, November 10). Https://Training.Cochrane.Org/Handbook/Current. /handbook/current 
Currell, S. D., Liaw, A., Blackmore Grant, P. D., Esterman, A., \& Nimmo, A. (2019). Orthodontic mechanotherapies and their influence on external root resorption: A systematic review. American Journal of Orthodontics and Dentofacial Orthopedics: Official Publication of the American Association of Orthodontists, Its Constituent Societies, and the American Board of Orthodontics, 155(3), 313-329. https://doi.org/10.1016/j.ajodo.2018.10.015

Damanakis, G. (2018). The effect of diabetes mellitus in orthodontic tooth movement in rats. National and Kapodistrian University of Athens.

Egger, M., Smith, G., Schneider, M., \& Minder, C. (1997). Bias in meta-analysis detected by a simple, graphical test. BMJ (Clinical Research Ed.), 315(7109), 629-634. https://doi.org/10.1136/bmj.315.7109.629

Ferreira, C. L., da Rocha, V. C., da Silva Ursi, W. J., De Marco, A. C., Santamaria, M., Santamaria, M. P., \& Jardini, M. A. N. (2018). Periodontal response to orthodontic tooth movement in diabetes-induced rats with or without periodontal disease. Journal of Periodontology, 89(3), 341-350. https://doi.org/10.1002/JPER.17-0190

Fleming, P. S., Koletsi, D., Dwan, K., \& Pandis, N. (2015). Outcome discrepancies and selective reporting: impacting the leading journals? PloS One, 10(5), e0127495. https://doi.org/10.1371/journal.pone.0127495

Gomes, M. F., da Graças Vilela Goulart, M., Giannasi, L. C., Hiraoka, C. M., de Fátima Santana Melo, G., de Sousa, A. G. V., Nóbrega, C. J. P., Zangaro, R. A., \& Salgado, M. A. C. (2017). Effects of the GaAlAs diode laser $(780 \mathrm{~nm})$ on the periodontal tissues during orthodontic tooth movement in diabetes rats: histomorphological and immunohistochemical analysis. Lasers in Medical Science, 32(7), 1479-1487. https://doi.org/10.1007/s10103-017-2268-9

Gomes, M. F., Goulart, M. da G. V., Giannasi, L. C., Hiraoka, C. M., Melo, G. de F. S., Zangaro, R. A., Nóbrega, C. J. P., \& Salgado, M. A. C. (2018). Effects of the photobiomodulation using different energy densities on the periodontal tissues under orthodontic force in rats with type 2 diabetes mellitus. Brazilian Oral Research, 32(0). https://doi.org/10.1590/1807-3107bor-2018.vol32.0061 
Guarneri, M. P., Weber, G., Gallia, P., \& Chiumello, G. (1993). Effect of insulin treatment on osteocalcin levels in diabetic children and adolescents. Journal of Endocrinological Investigation, 16(7), 505-509. https://doi.org/10.1007/BF03348892

Guo, Z., Chen, R., Zhang, F., Ding, M., \& Wang, P. (2018). Exendin-4 relieves the inhibitory effects of high glucose on the proliferation and osteoblastic differentiation of periodontal ligament stem cells. Archives of Oral Biology, 91, 9-16. https://doi.org/10.1016/j.archoralbio.2018.03.014

He, H., Liu, R., Desta, T., Leone, C., Gerstenfeld, L. C., \& Graves, D. T. (2004). Diabetes causes decreased osteoclastogenesis, reduced bone formation, and enhanced apoptosis of osteoblastic cells in bacteria stimulated bone loss. Endocrinology, 145(1), 447-452. https://doi.org/10.1210/en.20031239

Higgins, J. P. T., Thompson, S. G., Deeks, J. J., \& Altman, D. G. (2003). Measuring inconsistency in metaanalyses. BMJ (Clinical Research Ed.), 327(7414), 557-560. https://doi.org/10.1136/bmj.327.7414.557

Hofbauer, L. C., Brueck, C. C., Singh, S. K., \& Dobnig, H. (2007). Osteoporosis in patients with diabetes mellitus. Journal of Bone and Mineral Research: The Official Journal of the American Society for Bone and Mineral Research, 22(9), 1317-1328. https://doi.org/10.1359/jbmr.070510

Holtgrave, E. A., \& Donath, K. (1989). [Periodontal reactions to orthodontic forces in the diabetic metabolic state]. Fortschritte Der Kieferorthopadie, 50(4), 326-337. https://doi.org/10.1007/bf02164310

Hooijmans, C. R., Rovers, M. M., de Vries, R. B. M., Leenaars, M., Ritskes-Hoitinga, M., \& Langendam, M. W. (2014). SYRCLE's risk of bias tool for animal studies. BMC Medical Research Methodology, 14, 43. https://doi.org/10.1186/1471-2288-14-43

Jónsdóttir, S. H., Giesen, E. B. W., \& Maltha, J. C. (2006). Biomechanical behaviour of the periodontal ligament of the beagle dog during the first 5 hours of orthodontic force application. European Journal of Orthodontics, 28(6), 547-552. https://doi.org/10.1093/ejo/cjl050

Kato, H., Taguchi, Y., Tominaga, K., Kimura, D., Yamawaki, I., Noguchi, M., Yamauchi, N., Tamura, I., Tanaka, A., \& Umeda, M. (2016). High Glucose Concentrations Suppress the Proliferation of Human 
Periodontal Ligament Stem Cells and Their Differentiation Into Osteoblasts. Journal of

Periodontology, 87(4), e44-51. https://doi.org/10.1902/jop.2015.150474

Li, X., Zhang, L., Wang, N., Feng, X., \& Bi, L. (2010). Periodontal Ligament Remodeling and Alveolar Bone Resorption During Orthodontic Tooth Movement in Rats with Diabetes. Diabetes Technology \& Therapeutics, 12(1), 65-73. https://doi.org/10.1089/dia.2009.0085

Liberati, A., Altman, D. G., Tetzlaff, J., Mulrow, C., Gøtzsche, P. C., loannidis, J. P. A., Clarke, M., Devereaux, P. J., Kleijnen, J., \& Moher, D. (2009). The PRISMA statement for reporting systematic reviews and meta-analyses of studies that evaluate health care interventions: explanation and elaboration. Journal of Clinical Epidemiology, 62(10), e1-34. https://doi.org/10.1016/j.jclinepi.2009.06.006

Liu, R., Bal, H. S., Desta, T., Krothapalli, N., Alyassi, M., Luan, Q., \& Graves, D. T. (2006). Diabetes enhances periodontal bone loss through enhanced resorption and diminished bone formation. Journal of Dental Research, 85(6), 510-514. https://doi.org/10.1177/154405910608500606

Maia, L. G. M., Monini, A. da C., Jacob, H. B., \& Gandini, L. G. (2011). Maxillary ulceration resulting from using a rapid maxillary expander in a diabetic patient. The Angle Orthodontist, 81(3), 546-550. https://doi.org/10.2319/031110-141.1

Maulana, H., Hikmah, N., Shita, A. D. P., Permatasari, N., \& Widyarti, S. (2014). The Effect of Different Orthodontic Forces on MMP 9 Expression in a Rat Diabetic Model. 4(2), 7.

Mavrogonatou, E., \& Kletsas, D. (2012). Differential response of nucleus pulposus intervertebral disc cells to high salt, sorbitol, and urea. Journal of Cellular Physiology, 227(3), 1179-1187. https://doi.org/10.1002/jcp.22840

Mena Laura, E. E., Cestari, T. M., Almeida, R., Pereira, D. S., Taga, R., Garlet, G. P., \& Assis, G. F. (2019). Metformin as an add-on to insulin improves periodontal response during orthodontic tooth movement in type 1 diabetic rats. Journal of Periodontology, 90(8), 920-931.

https://doi.org/10.1002/JPER.18-0140 
Moher, D., Liberati, A., Tetzlaff, J., Altman, D. G., \& PRISMA Group. (2009). Preferred reporting items for systematic reviews and meta-analyses: the PRISMA statement. Journal of Clinical Epidemiology, 62(10), 1006-1012. https://doi.org/10.1016/j.jclinepi.2009.06.005

Najeeb, S., Siddiqui, F., Qasim, S. B., Khurshid, Z., Zohaib, S., \& Zafar, M. S. (2017). Influence of uncontrolled diabetes mellitus on periodontal tissues during orthodontic tooth movement: a systematic review of animal studies. Progress in Orthodontics, 18(1), 5. https://doi.org/10.1186/s40510-017-0159-z

Papadopoulou, A., Todaro, A., Eliades, T., \& Kletsas, D. (2019). Effect of hyperglycaemic conditions on the response of human periodontal ligament fibroblasts to mechanical stretching. European Journal of Orthodontics, cjz051. https://doi.org/10.1093/ejo/cjz051

Papadopoulou, K., Hasan, I., Keilig, L., Reimann, S., Eliades, T., Jäger, A., Deschner, J., \& Bourauel, C. (2013). Biomechanical time dependency of the periodontal ligament: a combined experimental and numerical approach. European Journal of Orthodontics, 35(6), 811-818.

https://doi.org/10.1093/ejo/cjs103

Plut, A., Sprogar, Š., Drevenšek, G., Hudoklin, S., Zupan, J., Marc, J., \& Drevenšek, M. (2015). Bone remodeling during orthodontic tooth movement in rats with type 2 diabetes. American Journal of Orthodontics and Dentofacial Orthopedics, 148(6), 1017-1025.

https://doi.org/10.1016/j.ajodo.2015.05.031

Reichert, C., Deschner, J., \& Jäger, A. (2009). Influence of diabetes mellitus on the development and treatment of malocclusions--a case report with literature review. Journal of Orofacial Orthopedics = Fortschritte Der Kieferorthopadie: Organ/Official Journal Deutsche Gesellschaft Fur Kieferorthopadie, 70(2), 160-175. https://doi.org/10.1007/s00056-009-0819-9

Review Manager (RevMan) [Computer program]. (2014). Copenhagen: The Nordic Cochrane Centre. The Cochrane Collaboration.

Santamaria-Jr, M., Bagne, L., Zaniboni, E., Santamaria, M. P., Jardini, M. A. N., Felonato, M., Santos, G. M. T., Mendonça, F. A. S., \& Esquisatto, M. A. M. (2019). Diabetes mellitus and periodontitis: Inflammatory 
response in orthodontic tooth movement. Orthodontics \& Craniofacial Research, ocr.12340.

https://doi.org/10.1111/ocr.12340

Sterne, J.A.C, Egger, M., \& Moher, D. (2011). Addressing reporting biases, Cochrane Handbook for Systematic Reviews of Intervention. Version 5.1.0. Cochrane Collaboration, Chichester, UK. http://www.cochrane-handbook.org/

Sterne, Jonathan A. C., Savović, J., Page, M. J., Elbers, R. G., Blencowe, N. S., Boutron, I., Cates, C. J., Cheng, H.-Y., Corbett, M. S., Eldridge, S. M., Emberson, J. R., Hernán, M. A., Hopewell, S., Hróbjartsson, A., Junqueira, D. R., Jüni, P., Kirkham, J. J., Lasserson, T., Li, T., ... Higgins, J. P. T. (2019). RoB 2: a revised tool for assessing risk of bias in randomised trials. BMJ (Clinical Research Ed.), 366, 14898. https://doi.org/10.1136/bmj.14898

Sun, J., Du, J., Feng, W., Lu, B., Liu, H., Guo, J., Amizuka, N., \& Li, M. (2017). Histological evidence that metformin reverses the adverse effects of diabetes on orthodontic tooth movement in rats. Journal of Molecular Histology, 48(2), 73-81. https://doi.org/10.1007/s10735-016-9707-y

Theodorou, C. I., Kuijpers-Jagtman, A. M., Bronkhorst, E. M., \& Wagener, F. A. D. T. G. (2019). Optimal force magnitude for bodily orthodontic tooth movement with fixed appliances: A systematic review. American Journal of Orthodontics and Dentofacial Orthopedics: Official Publication of the American Association of Orthodontists, Its Constituent Societies, and the American Board of Orthodontics, 156(5), 582-592. https://doi.org/10.1016/j.ajodo.2019.05.011

Verhaeghe, J., Suiker, A. M., Nyomba, B. L., Visser, W. J., Einhorn, T. A., Dequeker, J., \& Bouillon, R. (1989). Bone mineral homeostasis in spontaneously diabetic BB rats. II. Impaired bone turnover and decreased osteocalcin synthesis. Endocrinology, 124(2), 573-582. https://doi.org/10.1210/endo$124-2-573$

Villarino, M. E., Lewicki, M., \& Ubios, A. M. (2011). Bone response to orthodontic forces in diabetic Wistar rats. American Journal of Orthodontics and Dentofacial Orthopedics, 139(4), S76-S82. https://doi.org/10.1016/j.ajodo.2010.06.021 
Weltman, B., Vig, K. W. L., Fields, H. W., Shanker, S., \& Kaizar, E. E. (2010). Root resorption associated with orthodontic tooth movement: a systematic review. American Journal of Orthodontics and Dentofacial Orthopedics: Official Publication of the American Association of Orthodontists, Its Constituent Societies, and the American Board of Orthodontics, 137(4), 462-476; discussion 12A. https://doi.org/10.1016/j.ajodo.2009.06.021

Zhang, L., Li, X., \& Bi, L.-J. (2011). Alterations of collagen-I, MMP-1 and TIMP-1 in the periodontal ligament of diabetic rats under mechanical stress: Periodontal stress in diabetes mellitus. Journal of Periodontal Research, 46(4), 448-455. https://doi.org/10.1111/j.1600-0765.2011.01359.x 


\section{FIGURE CAPTIONS}

Figure 1. Flow diagram of study selection.

Figure 2. Risk of bias summary: review authors' judgements about each risk of bias item for each included study. The green plus sign indicates low risk of bias; the red minus indicates high risk of bias while the yellow question mark shows unclear risk of bias domains.

Figure 3. Random effects meta-analysis for the standardized mean difference in tooth movement induced by orthodontic forces between diabetic and normoglycemic rats.

Figure 4. Random effects meta-analysis for the standardized mean difference in the amounts of osteoclast cells within the compression sites of the periodontal ligament between diabetic and normoglycemic rats, after application of orthodontic forces.

Figure 5. Random effects meta-analysis for the standardized mean difference in the concentration of immunoreactive cells for anti- osteopontin (OPN) recorded 21 days after the initiation of tooth movement within the compression sites of the periodontal ligament between diabetic and normoglycemic rats. 


\section{TABLES}

Table 1. Characteristics of included studies $(n=14)$.

\section{Author Sample}

Arita et al., $\quad \mathrm{N}=23$, age: 10

2016

(Japan)

weeks, male

Sprague-

Dawley rats

Braga et al., $\quad \mathrm{N}=60$, age: 10

2011

(Brazil)

weeks, male

C57BL6/J mice

\section{Interventions}

A nickel-titanium closed-coil spring of $10 \mathrm{~g}$ was applied for 2 weeks to the maxillary left first molar in all rats to

induce mesial tooth movement. Intervention $A$

control normoglycemic $(n=7)$, Intervention B: diabetic

$(n=9)$, Interventions $C$ :

diabetic+ insulin $(n=7)$

An orthodontic appliance consisting of a nickeltitanium (Ni-Ti) $0.25 \cdot 0.76$ $\mathrm{mm}$ coil spring, bonded between the maxillary right first molar and the incisors and $35 \mathrm{~g}$ force in the mesia direction. Intervention $\mathrm{A}$ : control normoglycemic $(n=25)$, Intervention $B$ diabetic $(n=25)$, Interventions

C: diabetic+ insulin $(n=10)$

\section{Outcomes}

1. tooth movement, 2.

tooth inclination, 3 .

root resorption

1. tooth movement, 2. TRAP- positive

osteoclasts, 3. cytokine and chemokine

expression, 4

osteoblastic and

osteoclastic markers

(Alp, Col1, Runx2, Ocn)

\section{Method of outcome assessment}

microcomputed tomography

images

Timescin

14 days ( 2 weeks after STZ injection)

microscope and digital camera, real- time PCR

6 and $12 \mathrm{~d}$ for histological measurements; and 0,12 , and $72 \mathrm{~h}$ for biochemical analyses.

\section{Diabetes induction}

a single intraperitoneal injection of streptozotocin (STZ) $60 \mathrm{mg} / \mathrm{kg}$

intraperitoneal injection of $120 \mathrm{mg} / \mathrm{kg}$ of streptozotocin 
Damanakis $\mathrm{N}=16$, age: 4 (thesis), weeks, male

2018 Wistar rats

(Greece)

Ferreira et

al., 2018

(Brazil) weeks, male Wistar rats
A closed coil spring of $30 \mathrm{~g}$ was applied for 2 weeks to the maxillary right first molar in all rats to induce mesial tooth movement.

Intervention A: control

normoglycemic $(n=8)$,

Intervention B: diabetic $(n=8)$

$\mathrm{N}=40$, age: 13

A 4-mm closed-coil spring made of $\mathrm{CrNi}$ connected molars to incisors to induce
1. histologic and

outcomes, 2. tooth orthodontic tooth movement in groups with tooth

movement. Intervention $A$ : control normoglycemic w/o tooth movement,

Intervention B: control normoglycemic with tooth movement (OM)

Intervention C: control

normoglycemic with ligature induced periodontitis $(P)$,

Intervention D: control normoglycemic with OM and $\mathrm{P}$; Intervention $\mathrm{E}$ : diabetic, Intervention $\mathrm{F}$ : diabetic+ OM, Intervention $\mathrm{G}$ : diabetic+ $\mathrm{P}$, Intervention $\mathrm{H}$ : diabetic+

OTM+P ( $n=5$ each)

(bone mineral density) histochemical

movement

radiographs, casts, digital analysis of geometric image characteristics

21 days (1 week after SZT injection)

1. tooth movement, 2 . digital caliper, histologic histologic outcomes analyses
8 days (after initial 4 weeks for diabetes induction plus 1 week for periodontal disease induction) intraperitoneally with alloxan monohydrate in a sterile saline solution at a concentration of $150 \mathrm{mg} / \mathrm{kg}$ intraperitoneal

injection of

streptozotocin 60

$\mathrm{mg} / \mathrm{kg}$ 
1. A 4-mm closed-coil spring made of NiTi connected

molars to incisors with a

force magnitude of $20 \mathrm{cN}$ to

induce orthodontic tooth

movement

2. diode laser emission of

$780 \mathrm{~nm}$ wavelength, output

power of $20 \mathrm{~mW}$, energy

density of $640 \mathrm{~J} / \mathrm{cm} 2$ for $40 \mathrm{~s}$

on the middle third of the

root of the first molar.

Intervention groups $\mathrm{N}$ :

control normoglycemic, LN

laser-normoglycemic, D

diabetic, LD laser-diabetic

Each group was euthanized

at 7,14 and 21 days after

appliance installation $(n=5)$
1. histomorphological histologic analysis, outcomes,

immunohistochemical

2.immunohistochemical analysis

analysis

(OPN,OPG,RANKL)
7 days after diabetes was confirmed the appliance

was place remained from 7 up to 21 days intraperitoneally with alloxan

monohydrate at a

concentration of 40

$\mathrm{mg} / \mathrm{kg}$ 


\section{Li et al.,}

1.A 4-mm closed-coil spring made of NiTi connected molars to incisors with a

force magnitude of $20 \mathrm{cN}$ to induce orthodontic tooth movement

2. diode laser emission of

$780 \mathrm{~nm}$ wavelength, output power of $20 \mathrm{~mW}$, energy density of 160,320 ,

$640 \mathrm{~J} / \mathrm{cm} 2$ for $10,20,40$ s on the middle third of the root of the first molar. Each

animal received 10 doses of radiation

N normoglycemic,

160 J-LN 160 J-laser-

normoglycemic,

320 J-LN 320 J-laser-

normoglycemic,

640 J-LN640 J-laser-

normoglycemic,

D diabetic,

160 J-LD 160 J-laser-diabetic 320 J-LD 320 J-laser-diabetic 640 J-LD 640 J-laser-diabetic $\mathrm{n}=5$

1. NiTi coil force level $0.5 \mathrm{~N}$ between molars and incisors

"normal" $n=24$

"diabetes" n=24

the rats were euthanized 3 ,

7 , and 14 days after

orthodontic induction.
1. tooth movement,

2. histomorphological

analysis, 3 .

immunohistochemical

analysis (OPN) radiographs, histologic analysis,

immunohistochemical

analysis placed 7 days after diabetes was confirmed, 21 days intraperitoneally with alloxan

monohydrate at a concentration of 40 $\mathrm{mg} / \mathrm{kg}$
1. histological analysis, 2.immunohistochemical analysis
Col-I and Col-III fibers, expression of Col-I, MMp-1 and TIMP-1, osteoclasts count
3,7 and 14 days ( 8 weeks after diabetes was induced) single

intraperitoneal injection of STZ $65 \mathrm{mg} / \mathrm{kg}$ 
Maulana et $\mathrm{N}=24$, age: 4 al., 2014 month old,

(Indonesia) male, Wistar rats
1. Orthodontic appliance bonded to the upper incisors force magnitude 10,20,30 grF

K1 (normal, without

orthodontic appliances), K2

(diabetes, without

orthodontic appliances), K3

(normal, with orthodontic

appliance $30 \mathrm{grF}), \mathrm{K} 4$

(diabetes, with orthodontic

appliance $10 \mathrm{grF}$ ), $\mathrm{K} 5$

(diabetes, with orthodontic

appliance $20 \mathrm{grF}$ ), and $\mathrm{K} 6$

(diabetes, with orthodontic appliance $30 \mathrm{grF}$ )

Mena Laura $\mathrm{N}=100$, age: $8 \quad$ 1. A 9-mm NiTi closed coil et al., 2019 week old, male, spring between molars and

(Brazil)
Wistar rats incisors
NG $(n=20)$ control non

diabetic

T1D diabetic $(n=20)$ treated

with saline solution

I-T1D $(n=20) 2$ IU slow-

release insulin in the morning

and $2 \mathrm{IU}$ of regular plus $2 \mathrm{IU}$

of slow-release insulin in the evening. Total 6IU

IM-T1D $(n=20)$ treated as I-

T1D plus $150 \mathrm{mg} / \mathrm{kg}$ of

metformin
1. tooth movement, 2 . digital caliper, histologic histomorphological

analyses

analysis

7 days

imtraperitoneally with Streptozotocin stratified dose

(STZ-SD) of

$40,35,30,25,20$

$\mathrm{mg} / \mathrm{kg}$ for 5

consecutive days
1. tooth movement, 2. histological analysis, 3 . immunohistochemical analysis
micro-CT, histologic analysis, 14 days (2 weeks after STZ immunohistochemical analysis

\section{injection)}

single

intraperitoneal

injection of 47

$\mathrm{mg} / \mathrm{kg}$ of

streptozotocin 
Plut et al., $\quad \mathrm{N}=14$, age: $13-$ 2015

(Slovenia)

14weeks, male,

Wistar rats

$\mathrm{N}=14$, age: 13 -

14weeks, male,

GK rats

Santamaria $\quad \mathrm{N}=40$, age: 90

Jr et al., days, male,

$2019 \quad$ Wistar rats

(Brazil)

Sun et al.,

2016

$\mathrm{N}=30$, age: 7

weeks, male,

(China)
1. superelastic closed coil

spring $(25 \mathrm{cN})$ between molars and incisors.

Wistar control group ( $\mathrm{n}=8$ )

GK control group ( $n=8)$

Wistar appliance group ( $\mathrm{n}$

$=16$ )

appliance group ( $n=16$ )

1.ligature-induced

periodontitis

2.SS spring extended $2 \mathrm{~mm}$

(10 days, $0.4 \mathrm{~N}$ force); OTM:

orthodontic movement, $\mathrm{P}+$

OTM: periodontitis and

orthodontic movement, D +

OTM: diabetes and

orthodontic movement, $\mathrm{D}+\mathrm{P}$

+ OTM: diabetes,

periodontitis and orthodontic

movement ( $\mathrm{n}=10$ per group)

1. intragastric administration

of metformin $100 \mathrm{mg} / \mathrm{kg}$

14 days

expression, osteoclast count,

(SOST), dentin matrix protein 1 (DMP-1) NiTi 0.012 inch force of $0.5 \mathrm{~N}$.

(DB) type 2 diabetes group, $\mathrm{n}=10$; (MA) metformin
1. tooth movement, 2.

digital microscope, gene

alkaline phosphatase (ALP),

cathepsin $\mathrm{K}(\mathrm{CK})$, sclerostin

protein quantification in the gingival tissue and alveolar

bone

immunohistochemical

analysis spontaneous T2D

Goto-

Kakizaki (GK)

10 days ( 60 days after diabetes induction)

Alloxan-induced diabetes, 150 $\mathrm{mg} / \mathrm{kg}$ group, $\mathrm{n}=10 ;(\mathrm{NG})$

normoglycemic $n=10$ 
Villarino et $\mathrm{N}=24$, male, al., 2011

Wistar rats

(Argentina)

Zhang et

al., 2011

(China)
1. 0.014-in circular crosssection SS wire shaped into a helical spring force

magnitude of $120+/-15 g$

toward the vestibular plate

2. daily administration of

human NPH insulin

Experimental orthodontics

(ORT)

Experimental diabetes and

orthodontics (DBT+ORT)

Experimental diabetes

treated with insulin and

orthodontics (DBT 1 INS 1

ORT) ( $n=8$ per group)

$\mathrm{N}=48$, age: 6-7 1. NiTi coil between upper

weeks, male, incisor and upper 1st molar

Sprague-Dawley force level approx $50 \mathrm{~g}$

rats

nondiabetic (ND)

diabetes induced (DI) ( $n=24$

per group)
1. body weight, 2 .

histological analysis, 3.

histomorphometric

analysis

1. histological analysis, 2.immunoreactivity of collagen-I, MMP-1,

TIMP-1 histological analysis,

immunohistochemistry analysis (bone activity,

number of osteoclasts, bone

volume of the interradicular

bone) 48h (placed 6 weeks after

diabetes was induced)

4 rats in each group (ND,DI) were killed at 1, 3, 5, 7, 10 and $14 \mathrm{~d}$ after appliance placement (tooth movement 8 weeks after diabetes was induced) single

intraperitoneal injection of streptozotocin (STZ) $60 \mathrm{mg} / \mathrm{kg}$ 
Table 2. Quantitative data from meta-analyses and individual single studies for related outcomes (Diabetic vs Normoglycemic). The minus sign (-) shows lower effect for the diabetic group. Bold indicate statistically significant comparisons.

\begin{tabular}{|c|c|c|}
\hline \# & Study ID & Outcome \\
\hline 1 & 6 studies & Tooth movement \\
\hline 2 & 3 studies & Osteoclast cells (compression site) \\
\hline 3 & 2 studies & Immunoreactive cells for anti- OPN ( 21 days) \\
\hline \multirow[t]{2}{*}{4} & 1 study & Bone Loss $\left(\mathrm{mm}^{2}\right)$ \\
\hline & & Bone Density (\%) \\
\hline \multirow[t]{2}{*}{5} & 1 study & Root Resorption Area $\left(10^{4} \mu \mathrm{m}^{2}\right)$ \\
\hline & & Root Resorption Volume $\left(10^{6} \mu \mathrm{m}^{3}\right)$ \\
\hline \multirow[t]{2}{*}{6} & 1 study & Immunoreactive cells for anti- OPG (21 days) \\
\hline & & Immunoreactive cells for anti- RANKL (21 days) \\
\hline \multirow[t]{4}{*}{7} & 1 study & ALP expression (tension site) \\
\hline & & CK expression (compression site) \\
\hline & & SOST (cells/ mm²) (tension site) \\
\hline & & DMP- 1 (cells $/ \mathrm{mm}^{2}$ ) (tension site) \\
\hline \multirow[t]{6}{*}{8} & 1 study & bFGF* \\
\hline & & TGF- $\beta 1 *$ \\
\hline & & VEGF* \\
\hline & & Fibroblast cells ( $\mathrm{n} / 10^{4} \mu \mathrm{m}^{2}$ ) (tension site) \\
\hline & & Inflammatory cells $\left(\mathrm{n} / 10^{4} \mu \mathrm{m}^{2}\right)$ (tension site) \\
\hline & & Blood vessels ( $\mathrm{n} / 10^{4} \mu \mathrm{m}^{2}$ ) (tension site) \\
\hline
\end{tabular}

MD or SMD (95\% Cls)
SMD: $1.47(-0.60,3.53)$
SMD: $1.35(-3.40,6.10)$
SMD: $-3.77(-4.89,-2.66)$
MD: $0.06(-0.01,0.13)$
MD: $-4.5(-14.30,5.30)$
MD: $-18.7(-24.45,-12.95)$
MD: $-9.8(-14.65,-4.95)$
MD: $-0.77(-1.11,-0.43)$
MD: $-0.07(-0.27,0.13)$
MD: $-0.09(-0.10,-0.08)$
MD: $0.18(0.15,0.21)$
MD: $12(10.57,13.43)$
MD: $-17(-18.51,-15.49)$
MD: $91.3(72.46,110.14)$
MD: $96.05(83.86,108.24)$
MD: $68.7(57.03,80.37)$
MD: $-6.10(-8.39,-3.81)$
MD: $3(1.04,4.96)$
MD: $-0.4(-1.06,0.26)$

$\begin{array}{ll}\text { P-value } & \text { Hete } \\ 0.16 & 92 \\ 0.58 & 96 \\ <0.001 & 0 \\ 0.08 & - \\ 0.37 & - \\ <0.001 & - \\ <0.001 & - \\ <0.001 & - \\ 0.49 & - \\ <\mathbf{0 . 0 0 1} & - \\ <\mathbf{0 . 0 0 1} & - \\ <\mathbf{0 . 0 0 1} & - \\ <\mathbf{0 . 0 0 1} & - \\ <0.001 & - \\ <\mathbf{0 . 0 0 1} & - \\ <\mathbf{0 . 0 0 1} & - \\ <\mathbf{0 . 0 0 1} & - \\ \mathbf{0 . 0 0 3} & - \\ \mathbf{0 . 2 3} & -\end{array}$

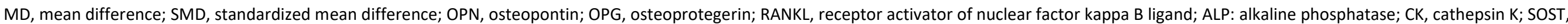
sclerostin; DMP- 1, dentin matrix protein 1; bFGF, fibroblastic growth factor; TGF- $\beta 1$, transforming growth factor; VEGF, vascular endothelial growth factor *protein quantification in the alveolar bone (inflammatory markers) 


\section{FIGURES}

Figure 1.

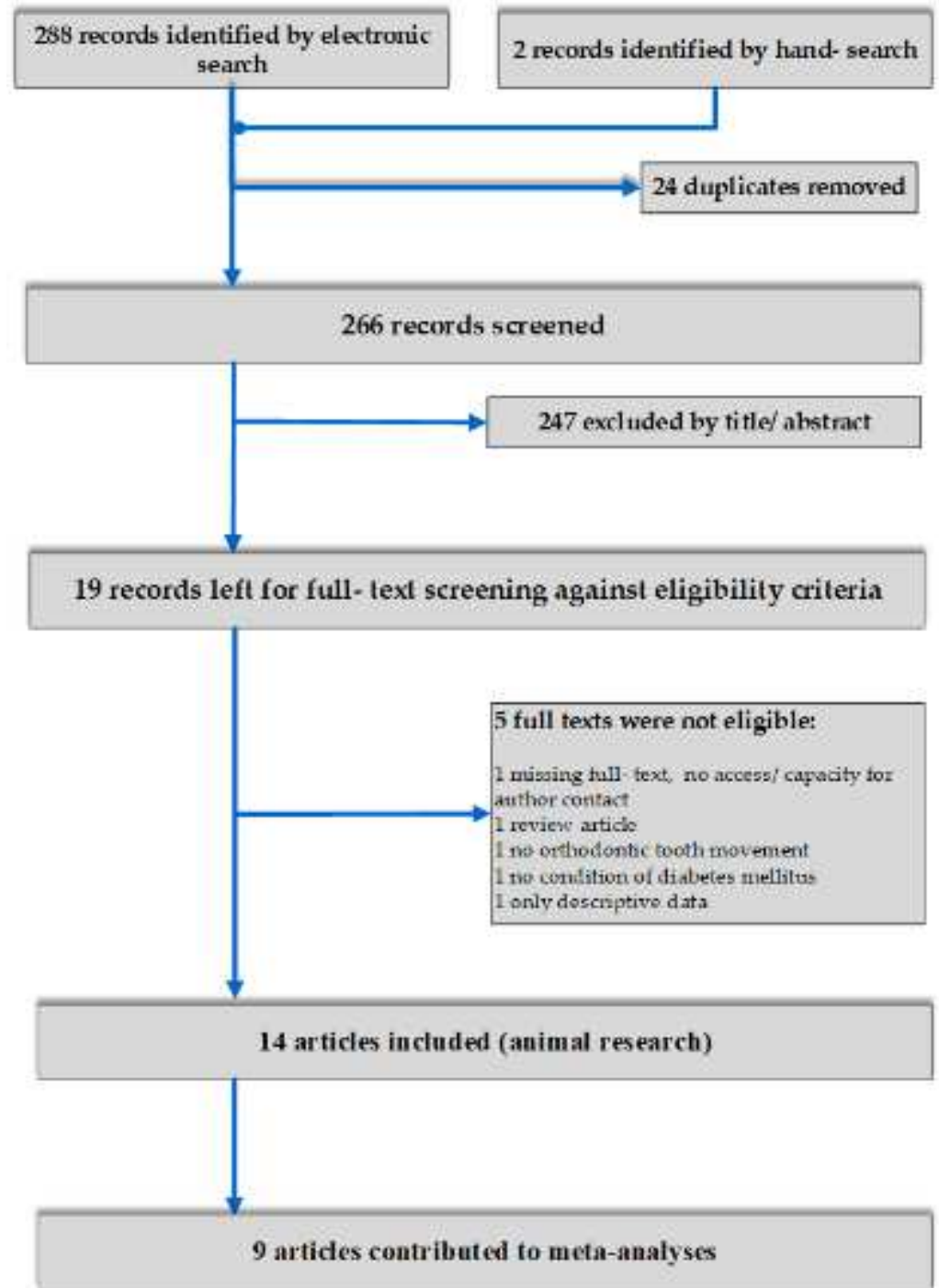


Figure 2.

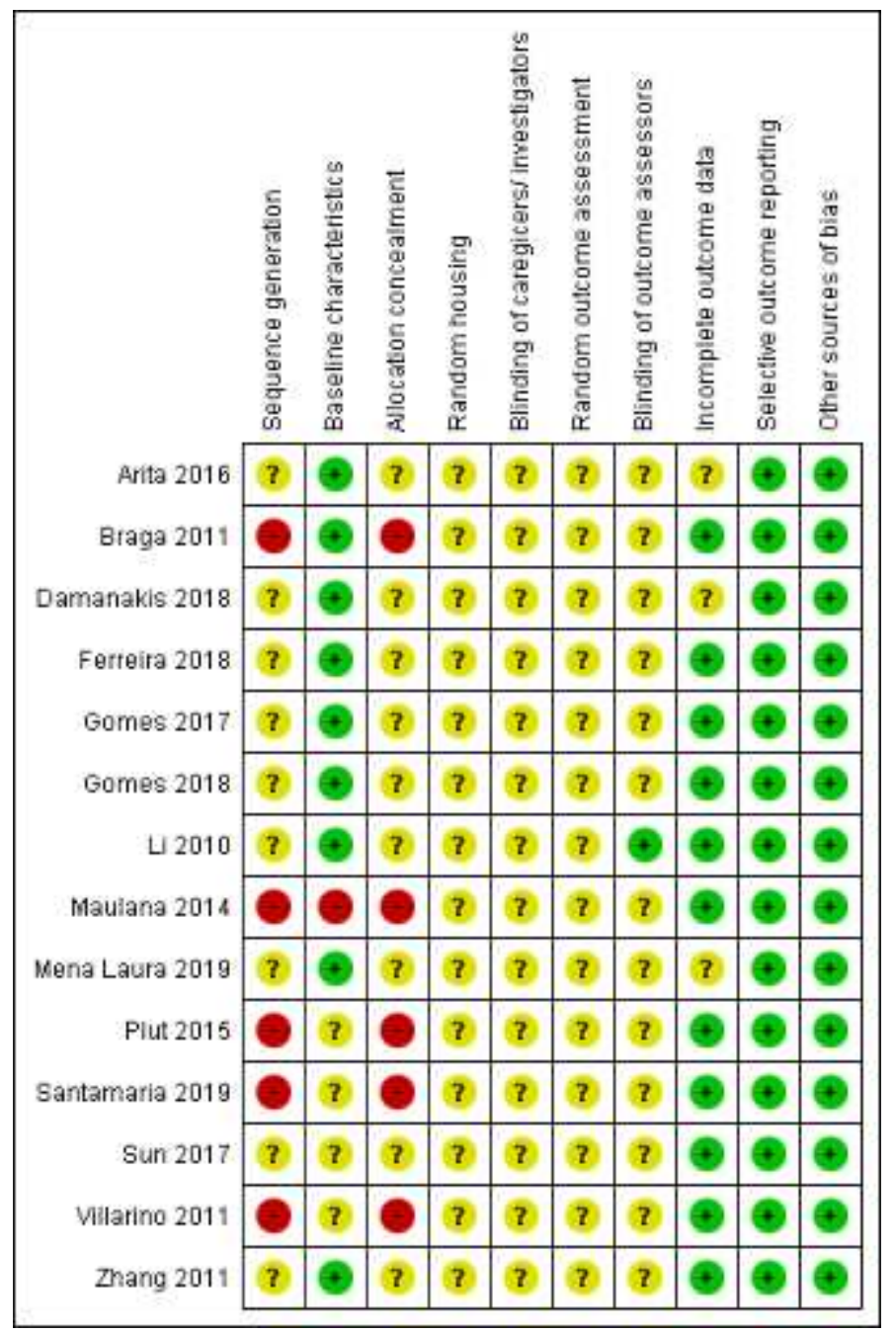




\section{Figure 3.}

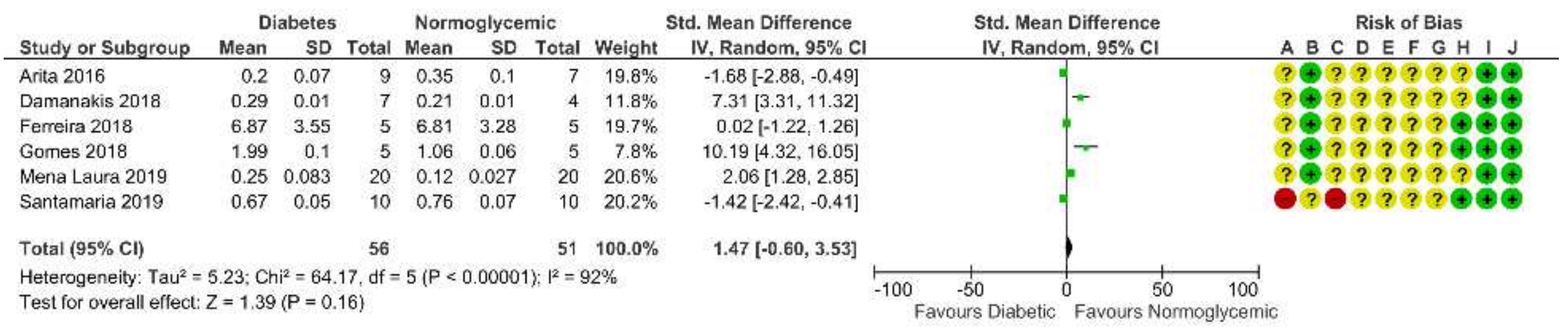

Risk of bias legend
(A) Sequence generation
(B) Baseline characteristics
(C) Allocation concealment
(D) Random housing
(E) Blinding of caregicers/ investigators
(F) Random outcome assessment
(G) Blinding of outcome assessors
(H) Incomplete outcome data
(1) Selective outcome reporting
(J) Other sources of bias 
Figure 4.

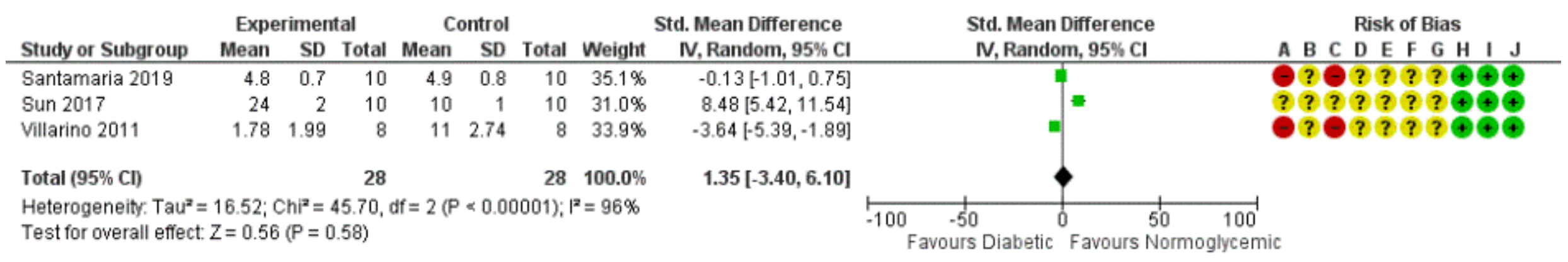

Risk of bias legend

(A) Sequence generation

(B) Baseline characteristics

(C) Allocation concealment

(D) Random housing

(E) Blinding of caregicers/ investigators

(F) Random outcome assessment

(G) Blinding of outcome assessors

(H) Incomplete outcome data

(I) Selective outcome reporting

(J) Other sources of bias 
Figure 5.

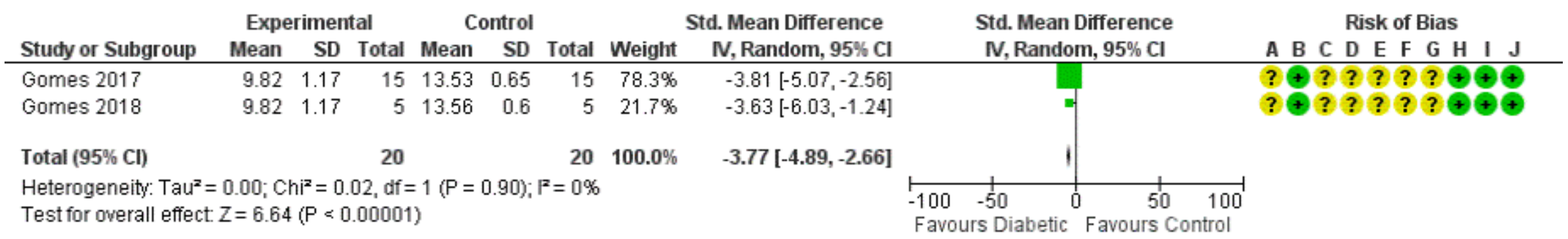

Risk of bias legend

(A) Sequence generation

(B) Baseline characteristics

(C) Allocation concealment

(D) Random housing

(E) Blinding of caregicers/ investigators

(F) Random outcome assessment

(G) Blinding of outcome assessors

(H) Incomplete outcome data

(I) Selective outcome reporting

(J) Other sources of bias 


\section{SUPPLEMENTARY FILES}

Supplementary Figure 1. Sensitivity analysis for the standardized mean difference in tooth movement induced by orthodontic forces between diabetic and normoglycemic rats, after excluding the study Santamaria et al., 2019 due to the inspection of high risk of bias.

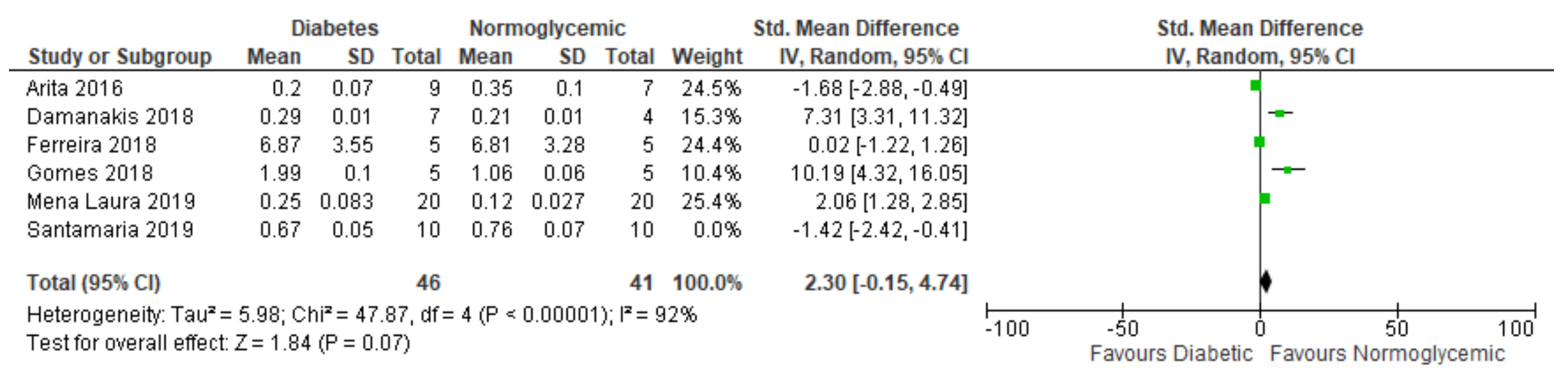


Supplementary Figure 2. Sensitivity analysis for the standardized mean difference in tooth movement induced by orthodontic forces between diabetic and normoglycemic rats, after excluding the study Damanakis 2018 due to the detection of extremely low variability of the treatment effects.

\begin{tabular}{|c|c|c|c|c|c|c|c|c|c|c|}
\hline \multirow[b]{2}{*}{ Study or Subgroup } & \multicolumn{3}{|c|}{ Diabetes } & \multicolumn{3}{|c|}{ Normoglycemic } & \multicolumn{2}{|r|}{ Std. Mean Difference } & \multirow{2}{*}{\multicolumn{2}{|c|}{$\begin{array}{l}\text { Std. Mean Difference } \\
\text { IV, Random, } 95 \% \mathrm{Cl}\end{array}$}} \\
\hline & Mean & SD & Total & Mean & SD & Total & Weight & IV, Random, 95\% Cl & & \\
\hline Arita 2016 & 0.2 & 0.07 & 9 & 0.35 & 0.1 & 7 & $22.6 \%$ & $-1.68[-2.88,-0.49]$ & 1 & \\
\hline Damanakis 2018 & 0.29 & 0.01 & 7 & 0.21 & 0.01 & 4 & $0.0 \%$ & $7.31[3.31,11.32]$ & & \\
\hline Ferreira 2018 & 6.87 & 3.55 & 5 & 6.81 & 3.28 & 5 & $22.5 \%$ & $0.02[-1.22,1.26]$ & & \\
\hline Gomes 2018 & 1.99 & 0.1 & 5 & 1.06 & 0.06 & 5 & $8.1 \%$ & $10.19[4.32,16.05]$ & $=$ & \\
\hline Mena Laura 2019 & 0.25 & 0.083 & 20 & 0.12 & 0.027 & 20 & $23.7 \%$ & $2.06[1.28,2.85]$ & 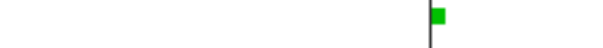 & \\
\hline Santamaria 2019 & 0.67 & 0.05 & 10 & 0.76 & 0.07 & 10 & $23.1 \%$ & $-1.42[-2.42,-0.41]$ & 1 & \\
\hline Total $(95 \%$ Cl) & & & 49 & & & 47 & $100.0 \%$ & $0.61[-1.43,2.64]$ & 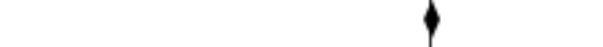 & \\
\hline $\begin{array}{l}\text { Heterogeneity: } \operatorname{Tau}^{2} \text { = } \\
\text { Test for overall effect }\end{array}$ & $\begin{array}{l}4.40 ; \mathrm{Cl} \\
\mathrm{Z}=0.58\end{array}$ & $\begin{array}{l}i^{2}=52 . \\
(P=0.5\end{array}$ & $\begin{array}{l}50, d f= \\
56)\end{array}$ & $=4(\mathrm{P}$. & .0000 & & & & $\begin{array}{l}1 \\
-50 \\
\text { Favours Diabetic }\end{array}$ & $\begin{array}{l}50 \\
\text { rmoglycemic }\end{array}$ \\
\hline
\end{tabular}


Supplementary Figure 3. Exploratory analysis for the standardized mean difference in tooth movement induced by orthodontic forces between diabetic (experimental) and insulin- treated (control) diabetic rats.

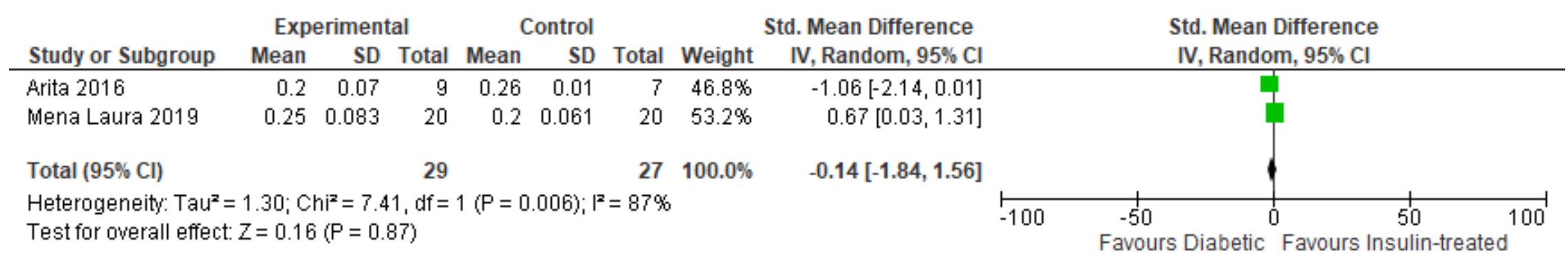

